\title{
Progress with a gas-accepting ion source for Accelerator Mass Spectrometry
}

\author{
M.L. Roberts, K.F. von Reden, C.P. McIntyre, and J.R. Burton \\ Woods Hole Oceanographic Institution, Woods Hole, MA 02543 USA
}

\begin{abstract}
The National Ocean Sciences AMS (NOSAMS) facility at Woods Hole Oceanographic Institution has developed a novel, gas-accepting microwave-plasma ionsource. The source is a key component of a compact Accelerator Mass Spectrometry (AMS) system built for the analysis of ${ }^{14} \mathrm{C}$ in a continuously flowing gas stream. The gas source produces carbon currents from a stream of $\mathrm{CO}_{2}$ with currents typical of a traditional graphite source. Details of the gas source, including ion current achieved, optimal flow rate, efficiency, and memory are presented. Additionally, data obtained from coupling a gas chromatograph to the source to will be shown. Details about ion optics are presented separately ${ }^{[1]}$.
\end{abstract}

PACS: 07.77 Ka; 52.50 Dg; 29.20 Ba

Keywords: Accelerator Mass Spectrometry, Gas Ion Source, Plasma Ion Source

\section{Introduction}

In traditional AMS, ion beams are produced by sputtering from prepared graphite targets. If the starting material is a complex mixture of compounds, the extraction and graphitization of individual compounds can be a laborious and time-consuming process. Furthermore, the process often yields only small amounts of graphite that is both difficult to handle and measure. In short, there is a poor match between the methods of analytical organic chemistry and AMS.

Directly connecting a gas-chromatograph or high-pressure liquid-chromatograph to an AMS system would be the 'Holy-Grail' of compound-specific ${ }^{14} \mathrm{C}$ analysis. Such a system would skip the graphitization step and allow relatively fast and easy measurements of specific compounds within complex mixtures. A system that could continuously monitor effluents of various interface devices would open new lines of inquiry in biogeochemistry and related fields. For example, such a system would allow (i) surveys of the distribution of ${ }^{14} \mathrm{C}$ among natural products and thus the sources of those materials ${ }^{[2]}$, (ii) recognition of fossil-fuel-derived pollutants in natural systems by exploiting their zero content of ${ }^{14} \mathrm{C}$ as a 'negative label ${ }^{\text {, } 3]}$, and (iii) quantification of ${ }^{14} \mathrm{C}$ tracers at extraordinary levels of dilution.

For biomedical research, a system to process liquid-phase samples (i.e., such as the output of a high-pressure liquid-chromatograph) has been developed at the Massachusetts Institute of Technology (MIT) ${ }^{[4]}$. The ion source used in this system is a 'hybrid' gas ion source in which $\mathrm{CO}_{2}$ is directed to and adsorbed by a titanium frit from which $\mathrm{C}^{-}$ions are extracted. While adequate in the MIT system, hybrid sources, in general, tend to have high sample-to-sample memory and produce relatively low ion currents.

In short, hybrid gas ion sources are less than ideal for environmental research where the difference in the ${ }^{14} \mathrm{C}$ content of chromatographic peaks can be small and high-currents (i.e., high ${ }^{14} \mathrm{C}$ counting rates) are needed to achieve precise results. A high-current, lowmemory, gas-accepting ion source is needed. The gas ion source described below satisfies those requirements. 


\section{The Gas Ion Source}

The operating principle of the gas ion source used at NOSAMS is illustrated in Figure $1 . \mathrm{CO}_{2}$ is introduced (with or without Argon carrier gas) into a plasma chamber using a fused-silica capillary. A plasma is established (at or near the 'Electron Cyclotron Resonance' condition) using $2.45 \mathrm{GHz}$ microwaves and a solenoidal magnetic field. Positive ions (several $\mathrm{mA}$ ) are extracted from the plasma using a triode system. Negative ions are formed by charge-exchanging interactions with magnesium.

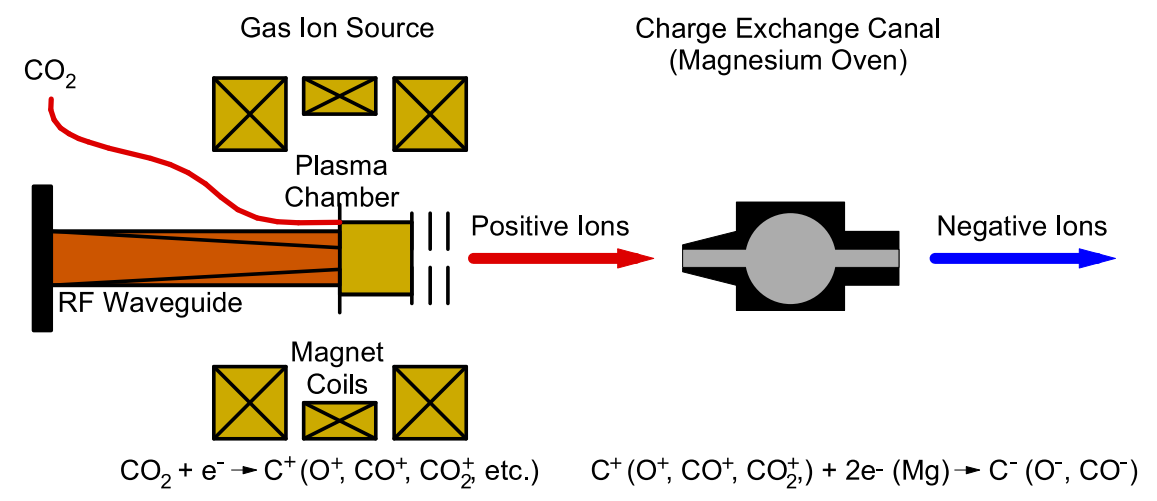

Figure 1. Operating principle of the gas ion source.

A cross-sectional view of the gas ion source is shown in Figure 2. This source was modeled after a source originally built at Atomic Energy of Canada Limited, Chalk River, Ontario, Canada for $\mathrm{H}^{+}$beams and subsequently developed at NOSAMS ${ }^{[5,6,7]}$ for ${ }^{14} \mathrm{C}$ AMS. In comparison to the prototype, the newly constructed source has several improvements including: (i) improved control of the magnetic field (by using solenoid magnets rather than permanent magnets), (ii) the ability to operate at potentials higher than $30 \mathrm{kV}$, (iii) better (i.e., close) coupling to the magnesium charge-exchange canal, (iv) the use of commerciallyavailable brazed insulators (as opposed to polyvinyl acetate glued ceramic/metal joints), (v) a reduction in internal O-ring water seals, and (vi) improved alignment capability. 


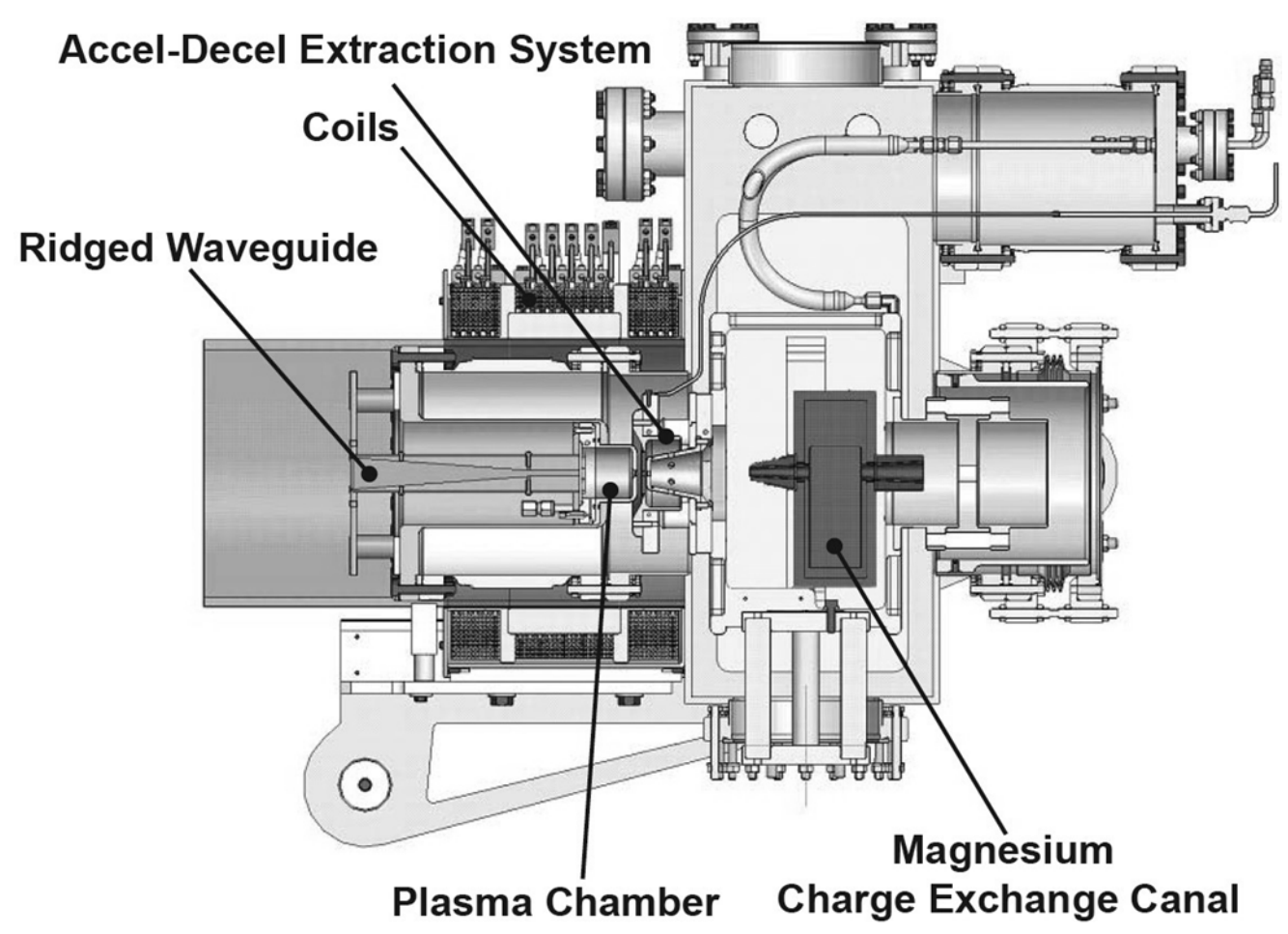

Figure 2. A cross-sectional view of the gas ion source.

A magnesium charge-exchange canal (purchased from Diamond Semiconductor Group, Gloucester, MA) is used to convert positive ions to negative ions. In our present setup, maximum $\mathrm{C}^{-}$currents are obtained at a temperature of about $445^{\circ} \mathrm{C}$. As discussed previously $^{[7]}$, a large energy spread (about $\pm 325 \mathrm{eV}$ at a nominal beam energy of $30 \mathrm{keV}$ ) is introduced into the beam during the charge-exchanging process. To efficiently transport a beam with such a large energy spread, the low-energy transport of the AMS system was designed to be energy-stigmatic. The first element of this achromat is a double-focusing $45^{\circ}$ electrostatic analyzer. Since the charge-exchange process from positive to negative ions is only about $12 \%$ efficient, a large flux of positive and neutral ions were hitting the electrostatic analyzer causing unstable operation. To alleviate this, the ion source was moved $7.5^{\circ}$ off-axis and a set of electrostatic deflection plates were installed at the object point of the analyzer. The plates deflect the negative ions by $7.5^{\circ}$, while the neutral and positive ions are discarded on a tantalum aperture plate.

Normally, the ion source operates between 30 and $35 \mathrm{kV}$ with respect to ground. An approximately $35 \mathrm{~cm}$ long section of fused-silica capillary provides electrical isolation between the source and whichever sample interface is used. The ion source, however, was designed so that the charge-exchange canal can be 'floated' to high voltage. Although not yet implemented, the plan is to operate the charge-exchange canal at $-30 \mathrm{kV}$ while maintaining the ion source at ground potential. The positive ions from the source would be accelerated towards the charge-exchange canal, undergo charge exchanging to become negative ions, and then further accelerated towards ground. The resulting 'tandem' charge-exchange canal will yield ion beams with a total energy of $60 \mathrm{keV}$ and eliminate any need for electrical isolation between the ion source and sample interface. Additionally, the higher energy beam would also have a lower emittance. 


\section{Results}

Initial characterization of the ion source commenced with the determination of the optimal $\mathrm{CO}_{2}$ flow rate. In operation, gas flows to the source via a $100-\mu \mathrm{m}$ inner diameter fused-silica capillary. By varying the length of the capillary, different gas flow rates are realized. Maximum ion-source output was obtained with a total capillary length of approximately $1.6 \mathrm{~m}$ corresponding to an actual $\mathrm{CO}_{2}$ flow rate of $370 \mu \mathrm{l} / \mathrm{min}$.

Table 1 lists source output, source efficiency, various transmission efficiencies, and total system efficiency. System efficiency was determined using the known $\mathrm{CO}_{2}$ flow rate and known ${ }^{14} \mathrm{C}$ content. Total system efficiency is defined as the total number of ${ }^{14} \mathrm{C}$ ions detected versus ${ }^{14} \mathrm{C}$ ions introduced into the source. A weak inverse-correlation was found between $\mathrm{CO}_{2}$ flow rate and system efficiency (i.e., lower flow rates gave higher efficiency).

Table 1. Typical source output and transmission efficiencies through various parts of the system.

\begin{tabular}{lr} 
Gas Flow $\left(\mathrm{CO}_{2}\right)$ & $370 \mu \mathrm{l} / \mathrm{min}$ \\
Low-Energy ${ }^{12} \mathrm{C}^{-}$ & $146 \mu \mathrm{A}$ \\
High-Energy ${ }^{12} \mathrm{C}^{+}$ & $42 \mu \mathrm{A}$ \\
${ }^{14} \mathrm{C}$ count Rate (from $\left.\mathrm{F}_{\mathrm{m}}=1.0438 \mathrm{CO}_{2}\right)$ & $408 \mathrm{cps}$ \\
& \\
Ion Source Efficiency $\left(\mathrm{C}^{+} /\right.$Molecule $\left.\mathrm{CO}_{2}\right)$ & $6.3 \%$ \\
Charge Exchange Canal Efficiency $\left(\mathrm{C}^{+}\right.$to $\left.\mathrm{C}^{-}\right)$ & $12 \%$ \\
Accelerator Transmission Efficiency $\left(\mathrm{C}^{-}\right.$to $\left.\mathrm{C}^{+}\right)$ & $29 \%$ \\
Beam Transport Efficiency (Bouncing Losses) & $<97.6 \%$ \\
\hline Total System Efficiency & $0.21 \%$
\end{tabular}

Source 'memory' was determined by alternately injecting 'live' and 'dead' $\mathrm{CO}_{2}$ into the gas source. Figure 3 shows ${ }^{14} \mathrm{C}$ counts versus time. The 'live' gas had a $\mathrm{F}_{\mathrm{m}}=1.0438$ while the 'dead' gas had a Fm $\approx 0.007$ (equivalent to a Libby age of $\approx 40,000 \mathrm{yrs}$ ). The retention time or 'memory' of the ion source could be fit with a curve having an exponential time constant of $\approx 2 \mathrm{~s}$. The majority of the memory can be explained by gas mixing/flushing within the approximately $100 \mathrm{ml}$ plasma chamber. We have plans to build a new, reduced volume plasma chamber which will presumably reduce gas retention time and hence 'memory'. Nevertheless, the present memory is more than adequate to cleanly resolve chromatographic peaks. 


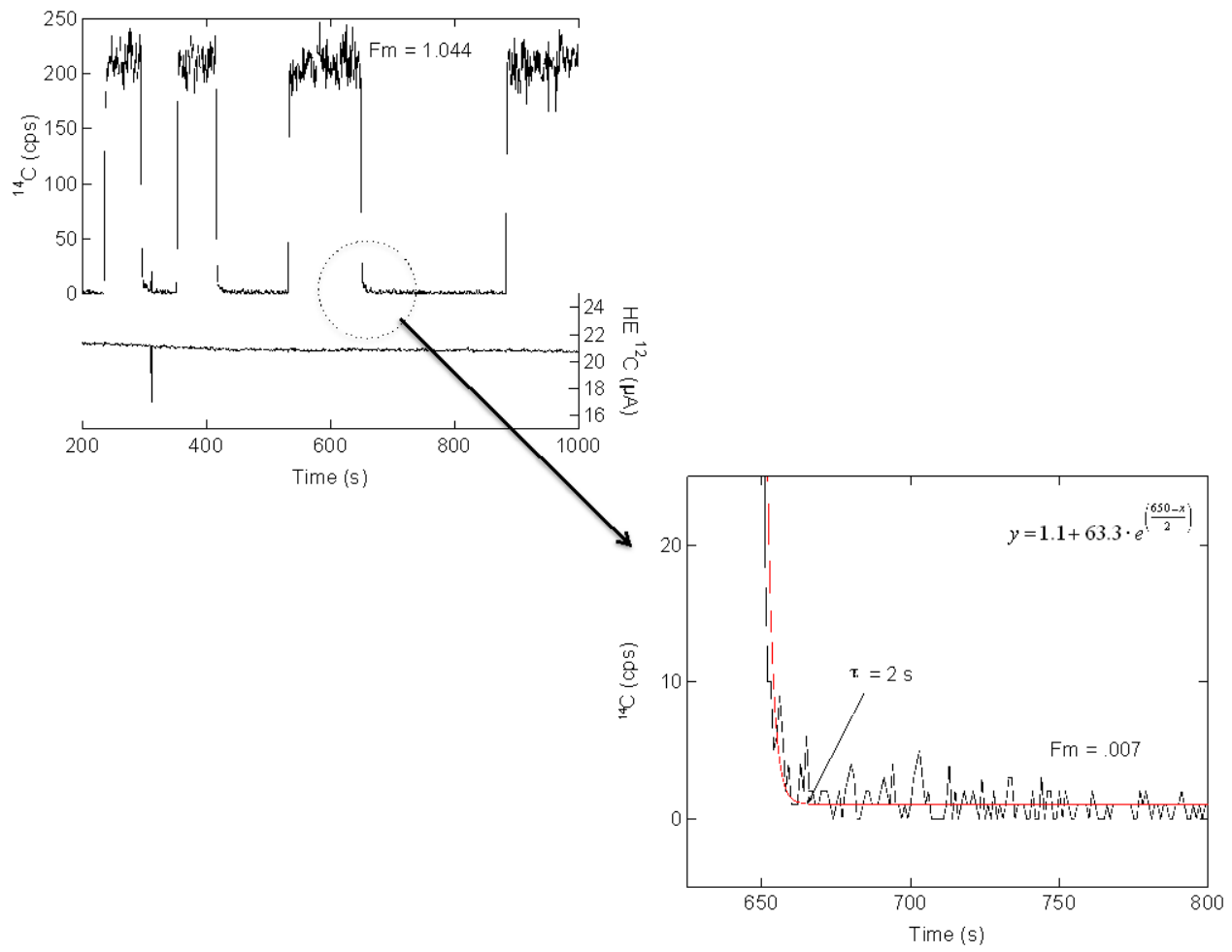

Figure 3. Source memory as 'live' and 'dead' $\mathrm{CO}_{2}$ were alternately introduced into the source. The 'memory' can be fit with an exponential curve having a time constant of $2 \mathrm{~s}$.

As a scientific proof-of-principle, we coupled a gas-chromatograph (GC) to the ionsource. The interface used is described in detail elsewhere ${ }^{[8]}$. An analysis of a bio-diesel sample using the system is shown in Figure 4. For this measurement, the bio-diesel sample was mixed with three reference compounds (a 'dead' $\mathrm{nC}_{16}$ alkane, and two 'modern' fatty acid methyl esters $\left(\mathrm{C}_{15}\right.$ and $\left.\mathrm{C}_{17}\right)$ ). The sample mixture was then injected into gas-GC, which contained a mega-bore capillary column. $\mathrm{H}_{2}$ was used as a carrier gas. The GC eluent was mixed with $\mathrm{O}_{2}$ and $\mathrm{Ar}$ and passed through a combustion oven where the individual compounds were combusted to $\mathrm{CO}_{2}$. Water vapor was removed using a nafion dryer. The $\mathrm{Ar}$ is unaffected by the combustion and is used as a carrier gas to sweep the $\mathrm{CO}_{2}$ to the source. 

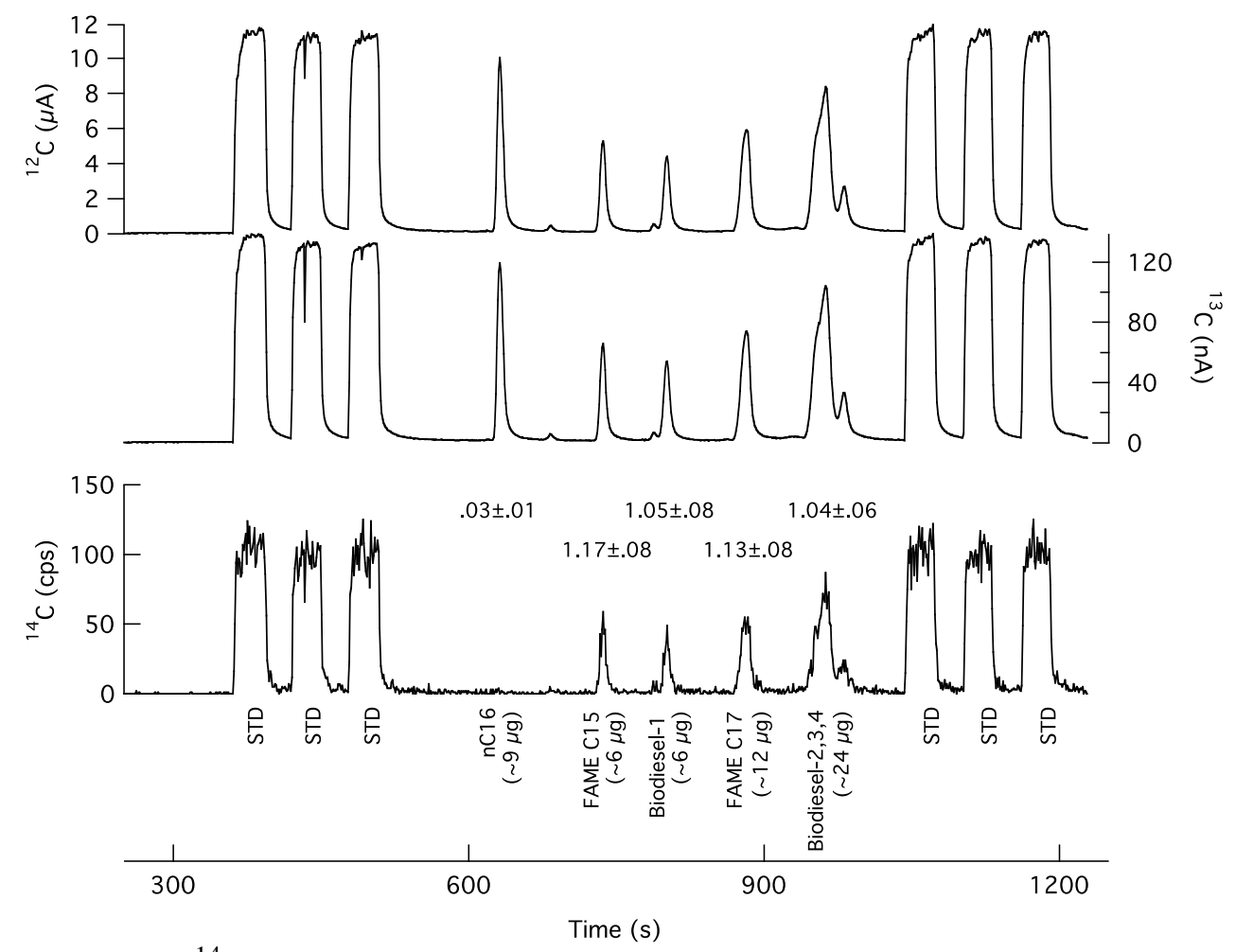

Figure 4. ${ }^{14} \mathrm{C}$ Gas chromatograph of biodiesel. Secondary standard $\mathrm{nC}_{16}$ is petroleum derived. Secondary standards FAME $\mathrm{C}_{15}$ and $\mathrm{C}_{17}$ are derived from 'modern' sources. The approximate mass of each compound is indicated below its name. STD indicates injection of reference gas $\left(\mathrm{F}_{\mathrm{m}}=1.0438\right)$ used for normalization. $\mathrm{F}_{\mathrm{m}}$ values for unknowns are given on the ${ }^{14} \mathrm{C}$ trace. As expected, the biodiesel has $\mathrm{F}_{\mathrm{m}}$ values consistent with current ${ }^{14} \mathrm{C}$ atmospheric levels.

\section{Conclusions}

We have developed a novel, low-memory, gas-accepting ion-source that produces ion currents typical of a traditional graphite source. A key advantage of a gas source is that, since the graphitization step in sample processing is eliminated, the total time required for sample analysis is shortened and the potential for sample-handling induced contamination is reduced. A key shortcoming of the gas ion source is its relatively low efficiency. Although continued refinement of the gas ion-source is expected to bring gains in efficiency and therefore sensitivity, the present source is ill suited for small samples and/or measurements requiring high precision.

We have coupled a gas-chromatograph to the source and achieved real-time compound-specific ${ }^{14} \mathrm{C}$ analysis of several materials at natural abundance levels. This represents a significant breakthrough in ${ }^{14} \mathrm{C}$ analysis and should prove useful for a variety of environmental and biomedical applications.

Finally, the characteristics of the ion source make it amenable to interfacing with a variety of other analytical instrumentation. Other possible interfaces include: (i) a programmable sampler for automated sample preparation and transfer of carbonates, (ii) an elemental analyzer for organic samples, (iii) a laser-combustion system for spatially resolved ${ }^{14} \mathrm{C}$ analysis, and (iv) a high performance liquid-chromatograph. 


\section{References}

[1] K.F. von Reden, M.L. Roberts, C.P. McIntyre, and J.R. Burton, Design and Reality: Continuous-flow Accelerator Mass Spectrometry, these proceedings.

[2] A. Pearson A., A.P. McNichol, B.C. Benitez-Nelson, J.M. Hayes, and T.I. Eglinton, Origins of lipid biomarkers in Santa Monica Basin surface sediment: A case study using compound-specific $\Delta 14 C$ analysis, Geochimica et Cosmochimica Acta, Volume 65, Issue 18, (2001), Pages 3123-3137.

[3] C.M. Reddy, T.I. Eglinton, A. Hounshell, H.K. White, L. Xu L, R.B. Gaines, and G.S. Frysinger, The West Falmouth Oil Spill after Thirty Years: The Persistence of Petroleum Hydrocarbons in Marsh Sediments. Environmental Science \& Technology, Volume 36 (22), (2002), Pages 4754-4760.

[4] J. Flarakos, R.G. Liberman, S.R. Tannenbaum, and P.L. Skipper, Integration of Continuous-Flow Accelerator Mass Spectrometry with Chromatography and Mass-Selective Detection. Analytical Chemistry, Volume 80 (13), (2008), Pages 5079-5085.

[5] J.S.C.Wills, R.A. Lewis, J. Diserens, H. Schmeing, and T. Taylor, A compact high-current microwavedriven ion source, Review of Scientific Instruments, Volume 69, (1998), Pages 65-68.

[6] R.J. Schneider, K.F. von Reden, J.M. Hayes, J.S.C. Wills, W.G.E. Kern, and S.-W. Kim, Tests of positive ion beams from a microwave ion source for AMS, Nuclear Instruments and Methods in Physics Research Section B, Volume 172, (2000), Pages 252-256.

[7] M.L. Roberts, R.J. Schneider, K.F. von Reden, J.S.C. Wills, B.X. Han, J.M. Hayes, B.E. Rosenheim, and W.J. Jenkins, Progress on a Gas Ion Source for Continuous-Flow Accelerator Mass Spectrometry, Nuclear Instruments and Methods in Physics Research Section B, Volume 259, Issue 1, (2007), Pages 8387.

[8] C.P. McIntyre, S.P. Sylva, and M.L. Roberts, Gas Chromatograph-Combustion System for ${ }^{14} \mathrm{C}$ Accelerator Mass Spectrometry, Analytical Chemistry, Volume 81, Issue 15, (2009), Pages 6422-6428. 